\section{KẾT LUẬN}

U mõ nội tuỷ đoạn tuỷ cổ là bênh tương đối hiếm gặp, biểu hiện điển hình với tình trạng yếu liệt tứ chi tăng dân, có thể kèm theo các rối loạn vể cảm giác. Chụp cộng hưởng từ là phương pháp chủ yếu để chẩn đoán bệnh. Về phương pháp điêuu trị, việc cắt bán phân u được ưu tiên hơn là cắt toàn bộ mô u nhằm tránh tổn thương chức năng thân kinh. Tạo hình màng cứng giúp tăng hiệu quả giải ép lâu dài.

\section{TÀI LIẸU THAM KHẢO}

1. Ammerman BJ, Henry JM, De Girolami U, Earle KM. Intradural lipomas of the spinal cord. A clinicopathological correlation. J Neurosurg 1976; 44: 331-336.
2. Bhatoe HS, Singh $P$, Chaturvedi A, Sahai $K$, Dutta V, Sahoo PK. Nondysraphic intramedullary spinal cord lipomas: A review. Neurosurg Focus. 2005; 18:EC P1.

3. Lee $M$, Rezai $A R$, Abbott $R$, Coelho $D H$ Epstein FJ. Intramedullary spinal cord lipomas. J Neurosurg. 1995;82:394-400.

4. Naim Ur R, Salih MA, Jamjoom AH, Jamjoom ZA. Congenital intramedullary lipoma of the dorsocervical spinal cord with intracranial extension: Case report. Neurosurgery. 1994; 34:1081-3.discussion 1084.

5. Pathi $\mathbf{R}$, Kiley $\mathbf{M}$, Sage $\mathbf{M}$. Isolated spinal cord lipoma . J Clin Neurosci 2003; 10:692-694.

6. Sanli AM, Türkog lu E, Kahveci R, Sekerci Z. Intradural lipoma of the cervicothoracic spinal cord with intracranial extension. Childs Nerv Syst 2010; 26:847-852.

\title{
CHẤT LƯợNG CUộC SỐNG VÀ MộT Số YẾU Tố LIÊN QUAN Ở TRẺ VI THÀNH NIÊN 10-15 TUỔI ĐIỀU TRI ARV NGOẠI TRÚ TẠI BỆNH VIỆN NHI TRUNG ƯO'NG
}

\author{
Nguyễn Thị Hiền ${ }^{1}$, Nguyễn Văn Lâm², Mattias Larsson ${ }^{3}$, Linus Olson ${ }^{3}$,
} Nguyễn Thị Kim Chúc ${ }^{4}$, Trần Khánh Toàn ${ }^{4}$

\section{TÓM TẮT}

Muc tiêu: Mô tả chất lượng cuộc sống (CLCS) và một số yếu tố liên quan ở trẻ vị thành niên 10-15 tuổi nhiếm HIV đang điêu trị ARV ngoaii trú tại Bệnh viện Nhi trung ương. Đối tượng và phương pháp: Nghiên cứu cắt ngang được thực hiên trên 190 trẻ từ 10-15 tuổi nhiễm HIV đang được quản lý điêuu trị ARV ngoai trú tai Bênh viên Nhi trung ương từ 6-12/2020. CLCS được đánh giá bằng công cụ PedsQL 4.0 với 23 câu hỏi liền quan đến 4 lính vực về thể chất, tình cảm, xã hội và học tập. Điểm số càng cao tương ứng với CLCS càng tốt. Kết quả: Điểm trung bình CLCS chung 72,2 ; về sức khỏe thể chất 80,3 ; sức khỏe tâm lý xã hội 75,6; xã hội 82,2; cảm xúc 76,3; và học tập 68,3. Tỷ lệ CLCS tốt tính chung là 56,8\%; về sức khỏe thể chất $67,9 \%$; sức khỏe tâm lý xã hội $57,4 \%$; về xã hội $73,2 \%$, cảm xúc $57,9 \%$ và học tập $45,3 \%$. Trẻ thuộc các hộ gia đình nghèo, trẻ có NCS có học vẫn thấp (từ THCS trở xuống) và trẻ có thời gian từ nhà đến phòng khám từ 60 phút trở lên có $C L C S$ thấp hơn $(p<0,05)$. Kết luân: Trẻ vị thành niên nhiễm HIV đang điều trị ARV có CLCS cao ở hầu hết các lĩnh vực, trừ lĩnh vực học tập. Hộ gia đình nghèo, học vấn của NCS thấp và

\footnotetext{
${ }^{1}$ Trường Đại học Y Dược - ĐH Thái Nguyên ²Bênh viện Nhi Trung Ương

${ }^{3}$ Viện Karolinska, Thụy Điển, ${ }^{4}$ Đại học Y Hà Nội

Chịu trách nhiệm chính: Nguyễn Thị Hiền

Email: Hiennguyentn92@gmail.com

Ngày nhận bài: 18.6.2021

Ngày phản biện khoa học: 17.8.2021

Ngày duyệt bài: 24.8.2021
}

thời gian tiếp cận phòng khám dài là những yếu tố liên quan đến CLCS thấp ở trẻ vị thành niên.

Tư khóa: Chất lượng cuộc sống, vị thành niên, HIV, ARV, PedsQL.

\section{SUMMARY \\ QUALITY OF LIFE AND RELATED FACTORS IN HIV-INFECTED ADOLESCENTS AGED 10- 15 YEARS ON ANTIRETROVIRAL TREATMENT AT THE NATIONAL CHILDREN'S HOSPITAL IN 2020}

Objectives: To describe the quality of life (QoL) and its related factors in HIV-positive adolescents aged 10-15 years on antiretroviral treatment (ART) at the National Children's Hospital. Subjects and methods: A descriptive cross-sectional study of 190 HIV-infected children aged $10-15$ years taking ART at the National Children's Hospital from June to December 2020. The 23-item PedsQL ${ }^{T M}$ Generic Core Scales were used to measure 4 core dimensions of health: physical, emotional, social and school functions. Results: The average scores were 72.2 for total QoL; 80.3 for physical health; 75.6 for psychosocial health; 76.3 for emotional function; 82.2 for social function; and 68.3 for school function. The rates of good QoL were $56.8 \%$ in total; $67.9 \%$ for physical function; $57.4 \%$ for psychosocial health; $57.9 \%$ for emotional function; $73.2 \%$ for social function; and $45.3 \%$ for school function. Children living in poor families, who having caregivers with low education (from lower secondary school) and those who need at least 60 minutes to reach the clinic had lower $\mathrm{QoL}(\mathrm{p}<0.05)$. Conclusion: HIV-infected 
adolescents on ART have a relatively good QoL in almost all domains, except for school function. Low household economic condition, low educational level of caregiver and longer time to access the clinic are associated with low QoL in adolescents on ART.

Keywords: Quality of life, adolescents, HIV, ARVs, PedsQLTM.

\section{I. ĐĂT VẤN ĐỀ}

HIV/AIDS vẫn đang là một vấn đề sức khỏe quan trọng, để lại gánh nặng bệnh tật lâu dài cho trẻ em, đăc biệt ở các nước đang phát triển. Năm 2019, ước tính có khoảng 2,8 triẹu trẻ em và trẻ vị thành niên nhiễm HIV trên toàn cầu với 320.000 trẻ mắc mới [1]. Tại Việt Nam, tính đến quý 3 năm 2017, nhóm tuổi từ $14-19$ tuổi chiếm 3\% trong những người mới phát hiện nhiễm HIV [2]. Ước tính hiện nay cả nước có khoảng 5000 trẻ em và trẻ vị thành niên đang được điều trị thuốc kháng vi rút (ARV) [3]. Trẻ mang HIV gặp nhiều thách thức ở các lĩnh vực khác nhau, nhất là trong giai đoạn chuyển tiếp của tuổi vị thành niên [4].

Vị thành niên là một giai đoạn đặc biệt trong cuộc đời với những đặc trưng riêng về tẩm sinh lý. Các vấn đề thường xảy ra ở trẻ em nhiễm HIV là bị xã hội kỳ thị, tự ti, ức chế sự phát triển tâm sinh lý bình thường, phải điều trị ARV kéo dài, tái khám thường xuyên, và nghỉ học nhiều lần [5]. Trẻ em và trẻ vị thành niên có HIV đang điều trị ARV cũng thường có tỷ lệ thất bại điều trị virut gấp 2 lần so với người lớn.

Với những tiến bộ gần đây trong điều trị ARV, thời gian sống của người nhiễm HIV đã được tăng lên rõ rệt; CLCS của người bệnh ngày càng được quan tầm. Tuy nhiên, ở Việt Nam chưa có nhiều nghiên cứu về CLCS của trẻ nhiễm HIV ở độ tuổi vị thành niên. Vì vậy, chúng tôi tiến hành nghiên cứu này nhằm đánh giá CLCS và một số yếu tố liên quan ở trẻ vị thành niên nhiễm HIV đang điều trị ARV tại Bệnh viện Nhi trung ương năm 2020. Những thông tin này sẽ là cơ sở cho các can thiệp nhẳm cải thiện CLCS và hiệu quả điều trị của trẻ nhiễm HIV.

\section{II. ĐỐI TƯợNG VÀ PHƯƠNG PHÁP NGHIÊN CỨU}

2.1. Đối tượng nghiên cứu. Nghiên cứu được thực hiện trên đối tượng trẻ nhiễm HIV đang được quản lý điều trị ARV thường xuyên tại phòng khám ngoại trú (OPC) của Bệnh viện Nhi trung ương từ tháng 6/2020 đến tháng 12/2020. Đây là một phần kết quả điều tra ban đâu của một Dự án can thiệp về hố trợ tuân thủ điều trị (HIVCHI-2) nên nghiên cứu loại trừ những trường hợp trẻ do các cơ sở điêu trị ARV khác giới thiệu đến điều trị tạm thời tại Bệnh viện Nhi trung ương; trẻ sống trong các cơ sở chăm sóc tập trung, trẻ đang tham gia các nghiên cứu can thiệp khác về - tuân thủ điều trị ARV. Tổng cộng có 190/196 trẻ thoả mãn tiêu chuẩn và đồng ý tham gia nghiên cứu.

2.2. Phương pháp nghiên cứu: Thiết kế nghiên cứu mô tả cắt ngang thông qua phỏng vấn trẻ và người chăm sóc (NCS) về CLCS của trẻ bằng công cụ PedsQL 4.0. Công cụ PedsQL 4.0 với 23 câu hỏi về 4 lĩnh vực về thể chất, tình cảm, xã hội và học tập, phù hợp để đo lường CLCS liên quan đển sức khỏe ở trẻ em và trẻ vị thành niên từ 2-18 tuổi với giá trị và độ tin cậy cao. Điểm CLCS ở từng lĩnh vực được tính bằng cách lấy tổng số điểm các câu trả lời ở từng lĩnh vực chia cho số câu đã trả lời trong lĩnh vực đó. Từ đó, tính được điểm trung bình CLCS chung và điểm trung bình riêng cho sức khoẻ thể chất và sức khoẻ tâm lý xã hội. Điểm trung bình càng cao có nghĩa là CLCS của trẻ càng tốt và ngược lại. Trên cơ sở phổ điểm, trong nghiên cứu này, trẻ được coi là CLCS tốt khi điểm trung bình CLCS $\geq 75$. Thông tin về tiền sử, bệnh sử, đặc điểm lâm sàng, cận lâm sàng và điêu trị được thu thập từ hồ sở bệnh án ngoại trú và phỏng vấn bố sung NCS bằng một bộ cầu hỏi cấu trúc. Số liệu được phân tích bằng phần mềm SPSS 22.0. Nghiển cứu nằm trong khuôn khổ Dự án HIVCHI-2 đã được Hội đồng đạo đức của trường Đại học Y Hà Nội phê duyệt, bảo đảm các yêu cầu về đạo đức trong nghiên cứu y sinh học.

\section{KẾT QUẢ NGHIÊN CỨU}

\section{1. Đặc điểm chung của đối tượng} nghiên cứu

Bảng 1. Thông tin nhân chung của trẻ nhiếm HIV

\begin{tabular}{|c|c|c|}
\hline \multicolumn{2}{|c|}{ Thông tin của đối tượng } & Số lượng (\%) \\
\hline \multicolumn{2}{|c|}{ Tuối (năm) $12,1 \pm 1,7$} \\
\hline \multirow{2}{*}{ Giới tính } & Nam & $107(56,3 \%)$ \\
\cline { 2 - 3 } & Nữ & $83(43,7 \%)$ \\
\hline Địa bàn sinh & Hà Nội & $91(47,9 \%)$ \\
\cline { 2 - 3 } sống & Tỉnh khác & $99(52,1 \%)$ \\
\hline Thời gian từ & $30-<60$ phút & $51(26,84 \%)$ \\
\cline { 2 - 3 } $\begin{array}{c}\text { nơi ở đến } \\
\text { phòng khám }\end{array}$ & $60-<120$ phút & $56(29,5 \%)$ \\
\cline { 2 - 3 } & $\geq 120$ phút & $83(43,7 \%)$ \\
\hline Trẻ dân tộc thiếu số & $6(3,2 \%)$ \\
\hline Gia đình trẻ thuộc hộ nghèo & $62(32,6 \%)$ \\
\hline Trẻ có bảo hiếm y tế & $187(98,4 \%)$ \\
\hline Trẻ có được đến trường học & $185(99,5 \%)$ \\
\hline
\end{tabular}

Trong bảng 1 , trẻ nam chiếm tỷ lệ cao hơn nữ $(56,3 \%$ và $43,7 \%)$; độ tuổi trung bình là $12,1 \pm 1,7$. Hầu hết trẻ là người dân tộc Kinh $96,8 \%$, có bảo hiểm y tế $(98,4 \%)$, sống chủ yếu ở các tỉnh ngoài Hà Nội $(52,1 \%)$, gia đình chủ 
yếu 3-4 người $(56,3 \%)$ và được đến trường $(99,5 \%)$. Khoảng $1 / 3$ số trẻ thuộc các hộ gia đình nghèo.

Bảng 2. Thông tin đặc điểm lâm sàng, cận lâm sàng, điều trị ARV

\begin{tabular}{|c|c|c|}
\hline \multicolumn{2}{|c|}{ Thông tin } & $\begin{array}{l}\text { Số lượng } \\
(\%)\end{array}$ \\
\hline \multicolumn{2}{|c|}{$\begin{array}{l}\text { Tuối trung bình khi được chấn } \\
\text { đoán nhiếm HIV (tháng) }\end{array}$} & $37,2 \pm 28,3$ \\
\hline \multicolumn{2}{|c|}{\begin{tabular}{|c|} 
Thời gian trung bình được điều trị \\
sau khi chẩn đoán (tháng)
\end{tabular}} & $13,2 \pm 19,1$ \\
\hline \multicolumn{2}{|c|}{$\begin{array}{l}\text { Thời gian điêuu trị ARV trung bình } \\
\text { (năm) }\end{array}$} & $8,2 \pm 2,8$ \\
\hline \multirow{3}{*}{ BMI hiện tại } & Suy dinh dưỡng & $29(15,3 \%)$ \\
\hline & Bình thường & $156(82,1 \%)$ \\
\hline & Thừa cân, béo phì & $5(2,6 \%)$ \\
\hline \multirow{2}{*}{$\begin{array}{l}\text { Nhiếm trùng cơ } \\
\text { hội lúc bắt đâu } \\
\text { điêuu trị }\end{array}$} & Không & $91(47,9 \%)$ \\
\hline & Có & $\begin{array}{c}99 \\
(52,1 \%)\end{array}$ \\
\hline \multirow{4}{*}{$\begin{array}{c}\text { GĐLS lúc bắt đâu } \\
\text { điều trị }\end{array}$} & Giai đoạn I & $106(56,4 \%)$ \\
\hline & Giai đoạn II & $33(17,6 \%)$ \\
\hline & Giai đoạn III & $30(15,9 \%)$ \\
\hline & Giai đoạn IV & $19(10,1 \%)$ \\
\hline \multirow{2}{*}{$\begin{array}{l}\text { Giai đoạn lâm } \\
\text { sàng hiện tại }\end{array}$} & Giai đoạn I & $182(97,9 \%)$ \\
\hline & Giai đoạn II & $4(2,1 \%)$ \\
\hline \multirow{2}{*}{$\begin{array}{l}\text { Tải lượng vi rút } \\
\text { gân nhất }\end{array}$} & Trên ngưỡng & $37(19,9 \%)$ \\
\hline & Dưới ngưỡng & $149(80,1 \%)$ \\
\hline \multirow{3}{*}{$\begin{array}{l}\text { Nông độ CD4 } \\
\text { gần nhất }\end{array}$} & CD4 $<500$ & $33(17,6 \%)$ \\
\hline & $500 \leq C D 4<1000$ & $109(58,3 \%)$ \\
\hline & CD4 $\geq 1000$ & $45(24,1 \%)$ \\
\hline \multirow{2}{*}{\begin{tabular}{|c|} 
Đã từng gặp thất \\
bại điểu trị
\end{tabular}} & Có & $44(23,2 \%)$ \\
\hline & Không & $146(76,8 \%)$ \\
\hline \multirow{2}{*}{$\begin{array}{c}\text { Tuân thủ điều trị } \\
\text { ARV hiện tại }\end{array}$} & Tốt & $173(91,1 \%)$ \\
\hline & Chưa & $17(8,9 \%)$ \\
\hline
\end{tabular}

Trung bình trẻ được chẩn đoán vào khoảng 37 tháng tuổi, được điêuu trị arv sau đó khoảng 13 tháng và thời gian điều trị trung bình 8,2 năm. Thời gian nhiểm HIV dưới 10 năm 52,6\%, có $95,2 \%$ trẻ được xác định lây nhiễm HIV theo đường mẹ con. NTCH khi bắt đâu điêu trị $52,1 \%$ và $43,6 \%$ ở giai giai đoạn lâm sàng II trở lên. Sau thời gian điều trị bằng $A R V$, đại đa số trẻ ở GĐLS I $(97,9 \%)$, với $80,1 \%$ có tải lượng virus dưới ngưỡng, và $17,6 \%$ có CD4 dưới 500 . Hiện tại $15,3 \%$ trẻ suy dinh dưỡng và $5,6 \%$ trẻ thừa cân, béo phì. Có $23,2 \%$ trẻ từng gặp thất bại điều trị $A R V$ về lâm sàng, miễn dịch và hoặc vi rút học, phần lớn trẻ tuân thủ điều trị $A R V$ (91,1\%) (bảng 2).

Bảng 3. Thông tin chung NCS chính

\begin{tabular}{|c|c|c|}
\hline \multicolumn{2}{|c|}{ Thông tin của đối tượng } & Số lượng (\%) \\
\hline \multirow{3}{*}{ NCS chính } & Bố & $37(19,5 \%)$ \\
\cline { 2 - 3 } & Mẹ & $114(60,00 \%)$ \\
\cline { 2 - 3 } & Öng, bà & $29,26(15,3 \%)$ \\
\hline
\end{tabular}

\begin{tabular}{|c|c|c|}
\hline & Khác & $10(5,2 \%)$ \\
\hline \multicolumn{3}{|c|}{ 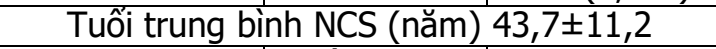 } \\
\hline \multirow{2}{*}{ Học vấn NCS } & $\begin{array}{l}\text { Từ PTTH } \\
\text { trở lên }\end{array}$ & $\begin{array}{c}88 \\
(46,3 \%)\end{array}$ \\
\hline & $\begin{array}{l}\text { Từ THCS } \\
\text { trở xuống }\end{array}$ & $\begin{array}{c}102 \\
(53,7 \%)\end{array}$ \\
\hline \multirow{2}{*}{$\begin{array}{l}\text { Nghề nghiệp } \\
\text { NCS }\end{array}$} & $\begin{array}{l}\text { Lao đô̂ng } \\
\text { phổ thông }\end{array}$ & $\begin{array}{c}111 \\
(58,4 \%)\end{array}$ \\
\hline & Khác & $79(41,6 \%)$ \\
\hline \multirow{3}{*}{$\begin{array}{c}\text { Tình trạng } \\
\text { nhiễm HIV của } \\
\text { người chăm sóc }\end{array}$} & Có & $137(72,1 \%)$ \\
\hline & Không & $37(19,5 \%)$ \\
\hline & Không rõ & $16(8,4 \%)$ \\
\hline
\end{tabular}

Bảng 3 cho thấy NCS chính chủ yếu là bố, me $(79,5 \%)$ với tuổi trung bình $43,7 \pm 11,2$ và phần lớn có học vấn NCS từ THCS trở xuống $(53,7 \%)$. Hầu hết NCS là lao động phổ thông $(58,4 \%)$. Tỷ lệ nhiễm HIV của NCS cao $72,1 \%$.

Bảng 4: Điểm trung binh CLCS của trẻ theo từng lĩnh vức, khía canh

\begin{tabular}{|c|c|c|c|c|c|}
\hline $\begin{array}{c}\text { CLCS } \\
\text { Lĩnh vựa }\end{array}$ & Q1 & Q2 & Q3 & Min & Max \\
\hline $\begin{array}{c}\text { Sức khỏe } \\
\text { thể chất }\end{array}$ & 65,3 & 87,5 & 100 & 25 & 100 \\
\hline Cảm xúc & 60,0 & 80,0 & 100 & 15 & 100 \\
\hline Xã hội & 70,0 & 90,0 & 100 & 0 & 100 \\
\hline Học tập & 55,0 & 70,0 & 85 & 0 & 100 \\
\hline $\begin{array}{c}\text { Sức khỏe } \\
\text { tâm lý xã hộ }\end{array}$ & 65,0 & 77,6 & 90 & 8,3 & 100 \\
\hline CLCS chung & 66,3 & 79,3 & 91,3 & 14,1 & 100 \\
\hline
\end{tabular}

Trong bảng 4 ĐTB CLCS chung và các lĩnh vực tương đối cao: CLCS chung 72,2; lĩnh vực sức khỏe thể chất 80,3 ; sức khỏe tâm lý xã hội 75,6 . Trong lĩnh vực sức khỏe tâm lý xã hội: ĐTB khía canh xã hội là cao nhất: 82,2 thấp nhất học tập: 68,3.

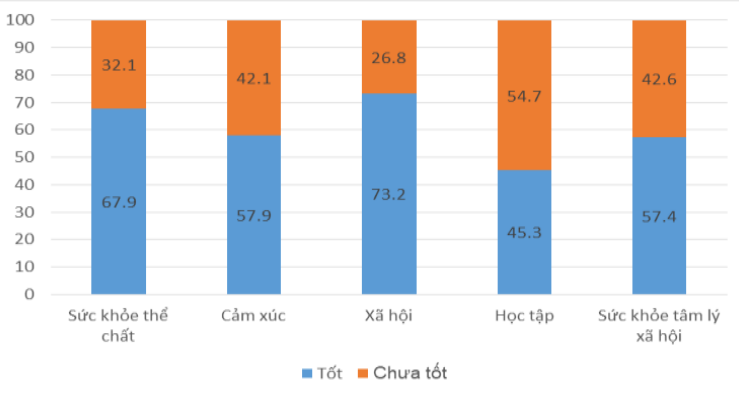

\section{Biểu đồ 1: Phân loai CLCS của từng lĩnh vức, khía canh}

Nhân xét: Phấn loại CLCS của trẻ ở các lĩnh vực là tương đối tốt. Tỷ lệ CLCS chung tốt $56,8 \%$; lính vực sức khỏe thể chất $67,9 \%$; sức khỏe tâm lý xã hội $57,4 \%$ trong đó khía cạnh xã hội phân loại tốt cao nhất 73,2\% khía cạnh học tập phân loại CLCS tốt chiếm tỷ lệ thấp nhất 45,3\% tiếp đển khía cạnh cảm xúc 57,9\% (biểu đồ 1). 
Bảng 5: Môi liên quan giữa CLCS và đặc điểm của trẻ nhiễm

\begin{tabular}{|c|c|c|c|c|c|c|}
\hline \multirow{2}{*}{\multicolumn{2}{|c|}{ Thông tin của đối tượng }} & \multicolumn{2}{|c|}{ Tốt } & \multicolumn{2}{|c|}{ Chưa tốt } & \multirow{2}{*}{$\begin{array}{c}\text { OR } \\
95 \% \mathrm{CI}\end{array}$} \\
\hline & & $\mathbf{n}$ & $\%$ & n & $\%$ & \\
\hline \multirow{2}{*}{ Giới tính } & Nam & 63 & 58,9 & 44 & 41,1 & 1,0 \\
\hline & Nũ̃ & 45 & 54,2 & 38 & 45,8 & $1,2(0,7-2,2)$ \\
\hline \multirow{2}{*}{ Nhóm tuổi } & $13-15$ & 62 & 56,4 & 38 & 43,6 & 1,0 \\
\hline & $10-12$ & 46 & 57,5 & 34 & 42,5 & $1,0(0,5-1,7)$ \\
\hline \multirow{2}{*}{ Hộ nghèo } & Không & 80 & 62,5 & 48 & 37,5 & 1,0 \\
\hline & Có & 28 & 45,2 & 34 & 54,8 & $2,0(1,1-3,7)^{*}$ \\
\hline \multirow{2}{*}{$\begin{array}{c}\begin{array}{c}\text { Thời gian đến phòng } \\
\text { khám }\end{array} \\
\end{array}$} & Dưới 60 phút & 36 & 70,6 & 15 & 29,4 & 1,0 \\
\hline & Từ 60 phút trở lên & 72 & 51,8 & 67 & 48,2 & $2,2(1,1-4,4) *$ \\
\hline \multirow{2}{*}{ Nhóm tuổi NCS } & Trên 45 tuối & 29 & 63,0 & 17 & 37,0 & 1,0 \\
\hline & Từ 45 tuối trơ xuống & 79 & 54,9 & 65 & 45,1 & $1,4(0,7-2,8)$ \\
\hline \multirow{2}{*}{ NCS nhiễm HIV } & Không & 25 & 67,6 & 12 & 32,4 & 1,0 \\
\hline & Có & 74 & 54,0 & 63 & 46,0 & $1,8(0,8-3,8)$ \\
\hline \multirow{2}{*}{ Trình độ NCS } & Từ PTTH trở lên & 58 & 65,9 & 30 & 34,1 & 1,0 \\
\hline & Từ THCS trở xuống & 50 & 49,0 & 52 & 51,0 & $2,0(1,1-3,6)^{*}$ \\
\hline \multirow{2}{*}{ Thời gian nhiễm HIV } & Dưới 10 năm & 62 & 62,0 & 38 & 38,0 & 1,0 \\
\hline & 10 năm trở lên & 46 & 51,1 & 44 & 48,9 & $1,6(0,9-2,8)$ \\
\hline \multirow{2}{*}{$\begin{array}{l}\text { Thời gian điều trị ARV } \\
\text { sau chẩn đoán(tháng) }\end{array}$} & Trong vòng 6 tháng & 64 & 59,3 & 44 & 40,7 & 1,0 \\
\hline & Trên 6 tháng & 44 & 53,7 & 38 & 56,3 & $1,3(0,7-2,2)$ \\
\hline \multirow{2}{*}{ Trẻ bị suy dinh dưỡng } & Không & 94 & 58,4 & 67 & 41,6 & 1,0 \\
\hline & Có & 14 & 48,3 & 15 & 51,7 & $1,5(0,7-3,2)$ \\
\hline \multirow{2}{*}{$\begin{array}{l}\text { Giai đoạn lâm sàng } \\
\text { hiện tại }\end{array}$} & I & 104 & 57,1 & 78 & 42,9 & 1,0 \\
\hline & II & 2 & 50,0 & 2 & 50,0 & $1,3(0,2-9,7)$ \\
\hline \multirow{2}{*}{$\begin{array}{l}\text { Kết quả CD4 } \\
\text { gần nhất }\end{array}$} & Dưới 500 & 23 & 67,6 & 11 & 32,4 & 1,0 \\
\hline & Từ 500 trở lên & 85 & 54,5 & 71 & 45,5 & $1,7(0,8-3,8)$ \\
\hline \multirow{2}{*}{$\begin{array}{l}\text { Tải lượng vi rút } \\
\text { gần nhất }\end{array}$} & Dưới ngưỡng & 89 & 58,2 & 64 & 41,8 & 1,0 \\
\hline & Trên ngưỡng & 19 & 51,4 & 18 & 48,6 & $1,3(0,6-2,7)$ \\
\hline \multirow{2}{*}{$\begin{array}{c}\text { Tiền sử thất bại } \\
\text { điều trị }\end{array}$} & Không & 87 & 59,6 & 59 & 40,4 & 1,0 \\
\hline & Có & 21 & 47,7 & 23 & 52,3 & $1,6(0,8-3,2)$ \\
\hline
\end{tabular}

(* có ý nghĩa thống kê với $\mathrm{p}<0,05$ )

Nhận xét: Hộ gia đình nghèo, học vấn của NCS thấp và thời gian tiếp cận phòng khám dài là những yếu tố liên quan đến CLCS thấp ở trẻ vị thành niên Không có mối liên quan giữa CLCS và một số đặc điểm kinh tế xã hội khác (giới tính, nhóm tuổi), các đặc điểm NCS (nhóm tuổi, tình trạng nhiếm HIV của NCS) và các đặc điểm lâm sàng, cận lâm sàng và thông tin điều trị ARV của trẻ (bảng 5).

\section{BÀN LUÂ̂N}

Trong 190 trẻ đủ tiêu chuẩn được thu nhận vào nghiên cứu, tuổi trung bình là $12,1 \pm 1,7$ (năm), tỷ lệ nam/nữ là $1,3 / 1$. Tuổi trung bình được chẩn đoán nhiễm HIV 37,2士28,3 (tháng). Trong nghiên cứu của $A C$ Ubesie và công sự; Brown và cộng sự ở Ibadan cũng cho thấy tuổi trung bình được chẩn đoán nhiễm HIV là 3 tuổi. Tuổi để chẩn đoán nhiễm HIV là khá muộn. Trong nghiên cứu này, thời gian trung bình được điều trị sau chẩn đoán là 13,2 $\pm 19,1$ (tháng), sớm hơn so với kết quả trong nghiên cứu của
Desmonde và cộng sự (2018) trên 135.479 trẻ từ 1-19 tuổi điêu trị ARV thấy $68 \%$ trong tổng số được điều trị ARV sau 24 tháng phát hiện nhiễm HIV. Với việc khả năng tiếp cận với điều trị ARV ngày một tốt hơn, hy vọng trẻ sẽ có nhiêu cơ hội để được điều trị sớm hơn. Tăng cường tiếp cận với ARV đã cho phép trẻ em nhiểm HIV giai đoạn đầu có thể sống sót khi trở thành trẻ vị thành niên. Trong nghiên cứu này, CLCS tổng thể của trẻ nhiễm HIV ở giai đoạn này là tương đối tốt, tỷ lệ CLCS chung tốt $56,8 \%$; lĩnh vực sức khỏe thể chất $67,9 \%$; sức khỏe tâm lý xã hội $57,4 \%$ trong đó khía cạnh xã hội phân loại tốt cao nhất 73,2\% khía canh học tập phân loại CLCS tốt chiếm tỷ lệ thấp nhất $45,3 \%$. CLCS trong nghiên cứu này tốt có thể do bệnh nhân đã điêu trị từ lâu thời gian điều trị ARV trung bình $8,2 \pm 2,8$ nên trẻ ổn định về lâm sàng, cận lâm sàng hơn nữa trẻ đã nhận thức được về bệnh và xác định điều trị lâu dài. Ảnh hưởing tiêu cực của trình trạng HIV trong gia đình chủ yếu thể hiện ở sức khỏe tâm lý xã hội của trẻ nhất là ở khía cạnh học tập 
với điểm trung bình 68,3 tỉ lê CLCS tốt ở khía cạnh này thấp nhất trong 4 khía cạnh. Điều này phù hợp với kết quả nghiên cứu về tác động của HIV đối với CLCS ở trẻ em của Sebi Das và cộng sự năm 2010 thì điểm học tập thấp nhất trong 4 khía cạnh với ĐTB là 69,23.

Trong nghiên cứu, sức khỏe thể chất tương đối cao có thể giải thích rằng trong nghiên cứu với hầu hết trẻ có BMI bình thường $(82,1 \%)$ có tổng số lượng CD4 trên 500 tế bào/mm $\mathrm{mm}^{3}(82,4 \%)$ cao và hầu hết trẻ ở giai đoạn lâm sàng I $(97,9 \%)$, trẻ không có nhiễm trùng cơ hội cũng cho thây việc duy trì chăm sóc sức khỏe hiên tai phù hợp. Ở lĩnh vực sức khỏe tâm lý xã hội khía cạnh học tập và cảm xúc có ĐTB, tỷ lệ CLCS tốt thấp hơn các khía cạnh còn lại có thể là do nhiếm HIV ảnh hưởng trực tiếp đến hệ thần kinh trung ương, gây tổn thương thần kinh và bệnh não [6]. Hơn nữa, trẻ nhiễm HIV giai đoạn đầu cũng có nguy cơ gặp các vấn đề về chức năng nhận thức, hành vi và cảm xúc. Những vấn đề về sự thiếu hụt trong chức năng điều hành hoặc tốc độ xử lý, rất có thể ảnh hưởng đến kết quả hoạt động của trường học [7]. Ngoài ra, có hai yếu tố quan trong giúp phân biệt HIV với hầu hết các bệnh mãn tính khác liên quan đến hoạt động của học tập. Một là sự kỳ thị của xã hội liên quan đến HIV, hai là liên quan đến ảnh hưởng của NTCH.

Kết quả nghiên cứu cho thây CLCS của trẻ bi ảnh hưởng nhiều bởi các yếu tố kinh tế xã hội như điều kiện kinh tế gia đình, học vấn của NCS, thời gian từ nhà đến phòng khám hơn là các đặc điểm tiền sử, lâm sàng, cận lâm sàng và điều trị. Trẻ sống trong hộ gia đình nghèo có CLCS chưa tốt cao hơn trẻ sống trong gia đình là hộ nghèo. Kết quả này trái ngược với nghiên cứu của Chalermkwan Kuntawee trẻ sống trong gia đình có thu nhập $\leq 5000$ Baht thì có CLCS cao hơn [8]. Việc sống trong gia đình có điều kiện kinh tế tốt sẽ tao điều kiên cho trẻ tham gia điều trị theo dõi tình trang bệnh sẽ tốt hơn nhóm trẻ còn lại, thêm vào đó trẻ có thể được hưởng những gì tốt nhất góp phần vào phát triển sức khỏe thể chất và tinh thần. Trình độ học vấn của NCS càng thấp thì CLCS càng thấp. Kết quả này khác so với nghiên cứu của Chalermkwan Kuntawee và cộng sự năm 2010 thì trình độ NCS không ảnh hưởng đến CLCS của trẻ [8]. NCS ảnh hưởng rất lớn đến trẻ nhiễm HIV, việc trẻ có được tiếp cận với chẩn đoán và điều trị sớm phụ thuộc nhiều vào hiểu biết của NCS. NCS càng có kiến thức sẽ càng có những hiểu biết thêm về bệnh và từ đó có thể chăm sóc trẻ tốt hơn. Thời gian từ nhà đến nơi khám bệnh càng lâu thì CLCS của trẻ càng thấp. Điều này có thể lý giải rằng việc đến phòng khám định kì và tốn thời gian quá lâu ảnh hưởng đến công việc của NCS, NCS sẽ không sắp xếp được thời gian đưa trẻ đi khám ảnh hưởng đến điều trị của trẻ dẫn đến giảm CLCS.

Trong nghiên cứu này, các đặc điểm về lâm sàng và cận lâm sàng không có mối liên quan với CLCS như các nghiên cứu trước đây của các tác giả khác. Chẳng hạn, các nghiên cứu trước đây các tác giả có chỉ ra rằng số lượng tế bào CD4 thấp là các yếu tố dự báo chất lượng cuộc sống thấp hay tỉ lệ thất bại điều trị cao dẫn đển CLCS thấp. Trong nghiên cứu của Behailu Tariku Derseh năm 2020 những trẻ có CLCS kém có nguy cơ thất bại về vi rút học cao hơn 2,6 lần so với những trẻ có CLCS tốt.

\section{KẾT LUẬN}

Trẻ vị thành niên nhiễm HIV đang điều trị ARV có CLCS tương đối tốt, nhưng cần quan tâm nhiều hơn đến sức khoẻ tâm lý xã hội, nhất là vấn đề học tập. Hộ gia đình nghèo, học vấn của NCS thấp và thời gian tiếp cận phòng khám dài là những yếu tố liên quan đến CLCS thấp ở trẻ vị thành niên. -

\section{TÀI LIÊU THAM KHẢO}

1. UNICEF (2019). The AIDS epidemic continues to take a staggering toll, but progress is possible, accessed 7/2019-2019, from https:// data. unicef.org/topic/hivaids/global-regional-trends/.

2. Bộ Y tế (2017). Báo cáo công tác phòng chống HIV/AIDS năm 2017 và nhiệm vụ trọng tâm năm 2018.

3. Cục phòng chống HIV/AIDS-Bộ Y tế (2013). HIV/AIDS tại Việt Nam ước tính và dự báo giai đoạn 2011-2015, Nhà xuất bản Y học, Hà Nội.

4. $A L$ Agwu, $L$ Fairlie (2013). Antiretroviral treatment, management challenges and outcomes in perinatally HIV-infected adolescents. J Int AIDS Soc 2013, 16(18579).

5. S Cohen, JA Ter Stege, AM Weijsenfeld, et al. (2015). Health-related quality of life in perinatally HIV-infected children in the Netherlands. AIDS Care, 27(10), 1279-1288.

6. Scharko AM (2006). DSM psychiatric disorders in the context of pediatric HIV/AIDS. AIDS Care, 18(5), 441-445.

7. Nicole Phillips, MSocSci, Amos Taryn (2016). HIV-Associated Cognitive Impairment in Perinatally Infected Children: A Meta-analysis. Pediatrics, 138(5), e20160893.

8. Kuntawee Chalermkwan, Fungladda Wijitr Kaewkungwal Jaranit, et al. (2010). Socia factors related to quality of life among HIV infected children in ubon Ratchathani Province, Thailand. Southeast Asian J Trop Med Public Health, 41(5) 1136-1144. 